\title{
DISTRIBUIÇÃO E ASSINATURA ISOTÓPICA DE Pb EM SEDIMENTOS DE FUNDO DA FOZ DO RIO GUAMÁ E DA BAÍA DO GUAJARÁ (BELÉM - PARÁ)
}

\author{
Suziane Nascimento Santos*, Jean Michel Lafon e José Augusto Martins Corrêa \\ Instituto de Geociências, Universidade Federal do Pará, CP 8608, 66075-110 Belém - PA, Brasil \\ Marly Babinski \\ Instituto de Geociências, Centro de Pesquisas Geocronológicas, Universidade de São Paulo, 05508-900 São Paulo - SP, Brasil \\ Fabiana Ferrari Dias e Maria Helena Tirolo Taddei \\ Comissão Nacional de Energia Nuclear, Laboratório de Poços de Caldas, Rod. Poços de Caldas-Andradas km 13, $37701-970$ \\ Poços de Caldas - MG, Brasil
}

Recebido em 4/11/10; aceito em 19/7/11; publicado na web em 2/9/11

\begin{abstract}
LEAD DISTRIBUTION AND ISOTOPE SIGNATURE IN BOTTOM SEDIMENTS OF GUAMA RIVER AND GUAJARA BAY (BELEM - PARA). Lead analyses in bottom sediments from the hydrographic system of Belem (Para) indicated low contents of this metal for the sediments from the Guama river, with no significant anthropogenic contribution. A concentration of $18.1 \pm 1.5 \mathrm{mg} \mathrm{kg}^{-1}$ and ${ }^{206} \mathrm{~Pb} / 207 \mathrm{~Pb}$ isotopic signature of $1.196 \pm 0.002$ are assigned for $\mathrm{Pb}$ from natural sources. On the other hand, the significant increase of $\mathrm{Pb}$ contents in the sediments from the Guajará bay, together with the decrease of ${ }^{206} \mathrm{~Pb} /{ }^{207} \mathrm{~Pb}$ ratios $\left(1.172<{ }^{206} \mathrm{~Pb} /{ }^{207} \mathrm{~Pb}<1.188\right)$ point to an anthropogenic lead contribution, originated by the industrial and urban activities of the city of Belem.
\end{abstract}

Keywords: Bottom sediments; Pb isotopes; Belem - PA.

\section{INTRODUÇÃOO}

Os sedimentos de fundo constituem um compartimento importante na avaliação da intensidade e forma de impacto a que os ecossistemas aquáticos estão sendo submetidos, por serem considerados sumidouros e possíveis fontes e contaminação destes ecossistemas. ${ }^{1}$ Esses sedimentos podem liberar os metais pesados para a coluna d'água, afetando a qualidade da mesma, ou podem ainda acumular metais pesados por adsorção em argilominerais ou complexação na matéria orgânica, facilitando a entrada dessas substâncias na cadeia alimentar através de organismos bentônicos. ${ }^{2}$

$\mathrm{O}$ estudo do $\mathrm{Pb}$ adquiriu grande importância em estudos ambientais quando se percebeu que, diferentemente de outros metais pesados, as assinaturas isotópicas do $\mathrm{Pb}$ de proveniência antropogênica são distintas da assinatura isotópica de origem natural, podendo, portanto, ser utilizadas como traçador das fontes de contaminação deste metal. ${ }^{3-6}$

A cidade de Belém, Pará, é construída sobre uma península sedimentar estuarina. ${ }^{7}$ Nos últimos 20 anos, vem sofrendo um crescimento populacional acelerado, passando de um pouco acima de 1 milhão de habitantes em 1990 para cerca de 2,3 milhões em 2010, com um expressivo crescimento periférico. Apesar de não ter indústrias de grande porte, a cidade produz uma carga elevada de efluentes domésticos, lançados diretamente ou não no sistema hidrográfico através de cerca de $30 \mathrm{~km}$ de canais naturais, formados por baías, rios, furos e igarapés. ${ }^{8}$ Esses canais deságuam no Rio Guamá e na Baía do Guajará, os quais constituem, juntos, o principal corpo hídrico receptor da carga de poluentes produzidos pelas atividades industriais e domésticas da cidade.

A Baía do Guajará situa-se a oeste de Belém e prolonga-se ao norte até encontrar o estuário do Rio Pará e a Baía do Marajó. Pertence ao sistema estuarino do Rio Pará, no qual a interação entre correntes fluviais, marés e regime de ondas confere ao ambiente condições hidrodinâmicas de alta energia. A dinâmica das águas, as

*e-mail: engsuzi@yahoo.com.br variações sazonais extremas são fatores importantes que influenciam na concentração do material em suspensão e na complexidade dos processos de sedimentação. ${ }^{9}$

A margem esquerda da Baía do Guajará é constituída por numerosas ilhas e canais, sobressaindo-se as Ilhas das Onças, Jararaquinha, Jararaca, Mirim e Jutuba, enquanto que a margem direita corresponde à orla de Belém. O Rio Guamá margeia a cidade de Belém pelo sul e constitui, juntamente com o Rio Acará, as principais fontes de águas fluviais da Baía do Guajará. A margem direita do Rio Guamá corresponde à orla da cidade, enquanto que, na margem esquerda, as Ilhas do Cumbu e Grande separam o rio do continente. Ao norte da cidade encontra-se o "furo" do Maguari, no qual deságuam vários rios menores que atravessam algumas das áreas mais industrializadas da cidade (Figura 1S, material suplementar).

Na última década, o sistema hidrográfico de Belém foi alvo de várias investigações geoquímicas sobre metais pesados, incluindo alguns estudos de assinatura isotópica de $\mathrm{Pb}$.

Na Baía do Guajará, a margem direita correspondendo à orla de Belém, representa a área de maior influência antropogênica do $\mathrm{Pb}$ e outros metais pesados, nos sedimentos de fundo com concentração total média de $38 \mathrm{mg} \mathrm{kg}^{-1}$ para o $\mathrm{Pb}$. Na margem esquerda do Rio Guamá o $\mathrm{Pb}$ foi o metal pesado que apresentou a maior concentração, com concentração total média de $54 \mathrm{mg} \mathrm{kg}^{-1}$. Um valor máximo de $72 \mathrm{mg} \mathrm{kg}^{-1}$ foi encontrado em uma amostra coletada próxima a um povoado situado na margem sudeste da Ilha do Cumbu. Surpreendentemente, essa área é considerada afastada, não recebendo maiores influências de atividade antrópica. ${ }^{10}$ Sedimentos de fundo próximo das ilhas da margem esquerda da Baía estuário Guajará forneceram teores de $\mathrm{Pb}$ entre 42,9 e 28,3 $\mathrm{mg} \mathrm{kg}^{-1}$, com média de 38,3 \pm 5,3 mg $\mathrm{kg}^{-1}$, encontrados por Saraiva, ${ }^{11}$ similar ao valor médio encontrado na orla de Belém por Corrêa e Pereira. ${ }^{10}$

Os estudos isotópicos de $\mathrm{Pb}$ em sedimentos de fundos no sistema hidrográfico de Belém foram, geralmente, realizados em locais próximo às fontes de contaminação. No Furo do Maguari, sedimentos de fundo indicaram razões isotópicas ${ }^{206} \mathrm{~Pb} /{ }^{207} \mathrm{~Pb}$ de $1,196-1,199$, enquanto que nos seus afluentes, como o Rio Mocajatuba que drena 
o setor norte de Belém, teores de $\mathrm{Pb}$ elevados de até $89 \mathrm{mg} \mathrm{kg}^{-1}$ com razões isotópicas ${ }^{206} \mathrm{~Pb} /{ }^{207} \mathrm{~Pb}$ de até 1,162 foram encontrados. ${ }^{12}$ Nos arredores do aterro sanitário de Belém, assinaturas isotópicas antropogênicas foram identificadas em solos e sedimentos de fundo do Rio Aurá, tributário do Rio Guamá, com valores ${ }^{206} \mathrm{~Pb} /{ }^{207} \mathrm{~Pb}$ de 1,174-1,146 e sedimentos do Lago Água Preta, reservatório de água de Belém, revelaram uma composição isotópica antropogênica do $\mathrm{Pb}$ $\left({ }^{206} \mathrm{~Pb} /{ }^{207} \mathrm{~Pb} \quad 1,166-1,176\right)$, em amostras próximas às zonas urbanizadas. ${ }^{12}$ Finalmente, duas amostras de sedimentos da orla de Belém, na Baía do Guajará, apresentaram razões isotópicas ${ }^{206} \mathrm{~Pb} /{ }^{207} \mathrm{~Pb}$ de 1,188 e 1,167 e de 1,193 para sedimentos da desembocadura de um tributário do Rio Guamá. ${ }^{13}$ Com base nesse conjunto de dados isotópicos, razões ${ }^{206} \mathrm{~Pb} /{ }^{207} \mathrm{~Pb}$ em torno de 1,20 e de 1,16 foram sugeridas para, respectivamente, $\mathrm{o} \mathrm{Pb}$ geogênico e a introdução de $\mathrm{Pb}$ no meio ambiente, devida à atividade industrial e/ou ocupação urbana. ${ }^{12}$ Esse valor da razão isotópica para o $\mathrm{Pb}$ antropogênico é compatível com a razão ${ }^{206} \mathrm{~Pb} /{ }^{207} \mathrm{~Pb}$ de 1,15 , encontrada em aerossóis no distrito industrial de Icoaraci, no setor norte de Belém, e considerada como representando uma contribuição de $\mathrm{Pb}$ industrial no $\mathrm{Pb}$ atmosférico. ${ }^{4}$

O objetivo deste trabalho foi investigar a distribuição dos teores de $\mathrm{Pb}$ em sedimentos de fundo das margens do Rio Guamá e da margem esquerda da Baía do Guajará, para avaliar as contribuições antropogênicas através da determinação de sua assinatura isotópica. Em complemento, pretendeu-se contribuir para estabelecer um valor de referência (background) para teor e assinatura isotópica do $\mathrm{Pb}$ no sistema hidrográfico de Belém. Cabe ressaltar também a importância em se analisar os elementos maiores, dentre eles, $\mathrm{Al}, \mathrm{Mg}$ e Fe, com o objetivo de correlacionar o teor de $\mathrm{Pb}$ com os metais apresentados anteriormente, para identificar, possivelmente, onde o metal $\mathrm{Pb}$ se apresentará distribuído nos sedimentos de fundo.

\section{PARTE EXPERIMENTAL}

\section{Amostragens}

Na margem direita do Rio Guamá foram selecionados 9 pontos de coleta com espaçamento médio entre os pontos de $1 \mathrm{~km}$, tendo como ponto de referência a desembocadura do Rio Aurá. Na margem esquerda foram coletadas 14 amostras de sedimentos de fundo tendo como referência as Ilhas do Cumbu e Grande, sendo 9 amostras coletadas ao norte, no curso principal do rio, e 5 ao sul dessas ilhas, com distância média de $2 \mathrm{~km}$ entre os pontos.

Na Baía do Guajará, utilizou-se 9 amostras de sedimentos de fundo da margem esquerda ao longo das Ilhas das Onças, Jararaca, Mirim e Jutuba, sendo uma proveniente de um igarapé da Ilha das Onças (IO-04) e uma amostra da orla de Belém (C.V.C), na margem direta, próxima à desembocadura do canal Val-de-Cans que despeja diariamente efluentes da cidade na baía previamente coletadas e estudadas por Saraiva. ${ }^{11}$ Os pontos de amostragem estão localizados na Figura 1S, material suplementar.

As amostras de sedimentos do Rio Guamá foram coletadas com auxílio de uma draga de Petersen, armazenadas em sacos plásticos, codificadas, acondicionadas e protegidas de iluminação. As amostras foram secas em uma estufa $\left(50^{\circ} \mathrm{C}, 24 \mathrm{~h}\right)$. Em seguida, foram desagregadas em gral de ágata e o material fino (fração silte + argila) foi extraído utilizando uma peneira de aço inox com $63 \mu \mathrm{m}$ de abertura de malha para análises mineralógicas, análises químicas e determinação das composições isotópicas de $\mathrm{Pb}$. As amostras da Baía de Guajará foram coletadas e armazenadas seguindo o mesmo procedimento. Para essas amostras, foram apenas determinadas as composições isotópicas de $\mathrm{Pb}$ e utilizados os teores de $\mathrm{Pb}$ determinados por Saraiva. ${ }^{11}$

\section{Análises mineralógicas}

A composição mineralógica da fração fina dos sedimentos foi determinada no Laboratório de Difração de Raios X do Instituto de Geociências da UFPA, segundo o método proposto por Reynolds e Moore. ${ }^{14}$ As análises de amostras da fração $<63 \mu \mathrm{m}$, preparadas pelo método do pó, e de lâminas orientadas da fração $<2 \mu \mathrm{m}$ foram realizadas com difratômetro de raios-X, marca Philips, modelo PW 1050 , com monocromador de grafite e tubo de anodo de cobre.

\section{Determinação da percentagem de matéria orgânica e da concentração de metais}

A determinação do percentual de matéria orgânica foi feita por calcinação a $550{ }^{\circ} \mathrm{C}$ de $3 \mathrm{~g}$ da amostra bruta levada à mufla $(4 \mathrm{~h})$, segundo a metodologia de Loring e Rantala. ${ }^{15}$

A determinação da concentração total dos metais foi realizada no Laboratório Comercial da ACME Ltda (Canadá). O procedimento padrão de tratamento das amostras inclui a dissolução de $250 \mathrm{mg}$ da amostra com uma combinação multiácida na proporção 2:2:1:1 de $\mathrm{H}_{2} \mathrm{O}$ $\mathrm{HF}_{-} \mathrm{HCLO}_{4}-\mathrm{HNO}_{3}$. Após evaporação em chapa quente, uma segunda etapa de dissolução ácida é realizada com 7,5 mL de HCL-50\%, para dissolver o resíduo em banho-maria $\left(>95^{\circ} \mathrm{C}\right)$ por $30 \mathrm{~min}$. A solução é transferida em seguida para tubos de prolipropileno, aferidos para $10 \mathrm{~mL}$ da solução HCL-5\%, para posterior análise por espectrometria de massa ICP-MS. O procedimento padrão de controle da qualidade analítica da ACME Ltda para análises químicas inclui a análise de amostra em duplicata e de padrão de referência DST6 (in-house standard).

\section{Análises geocronológicas ${ }^{210} \mathrm{~Pb}$}

Tendo em vista as grandes variações nas velocidades de sedimentação em ambientes estuarinos, ${ }^{16}$ a geocronologia ${ }^{210} \mathrm{~Pb}$ foi utilizada para a determinação das taxas de acumulação dos sedimentos de fundo do Rio Guamá e da Baía do Guajará, e com isso definir o tempo de acumulação das amostras coletadas com a draga de Petersen. As análises de ${ }^{210} \mathrm{~Pb}$ e ${ }^{226} \mathrm{Ra}$ foram realizadas no Laboratório da Comissão Nacional de Energia Nuclear em Poços de Caldas, MG. As atividades de ${ }^{210} \mathrm{~Pb}$ e ${ }^{226} \mathrm{Ra}$ foram determinadas por espectrometria gama. Os procedimentos experimentais foram descritos em detalhes por Cazotti ${ }^{17}$ e os dados analíticos foram apresentados por Dias et al. ${ }^{18}$ Para cálculo das idades e das taxas de acumulação, foi utilizado o modelo CRS (fluxo constante).

\section{Análises isotópicas do $\mathbf{P b}$}

As composições isotópicas de $\mathrm{Pb}$ foram determinadas em amostras lixiviadas no Laboratório de Geologia Isotópica, do Instituto de Geociências da UFPA (amostras da margem direita do rio Guamá), e no Laboratório de Geocronologia, do Centro de Pesquisas Geocronológicas do Instituto de Geociências da USP (amostras da margem esquerda do Rio Guamá e da Baía de Guajará), segundo os procedimentos experimentais descritos em Lafon et al. ${ }^{19}$ e Magdaleno e Ruiz, ${ }^{20}$ respectivamente.

No laboratório de geocronologia da UFPA, $3 \mathrm{~g}$ de amostra foram lixiviados com $\mathrm{HNO}_{3} 5 \mathrm{~mol} \mathrm{~L}^{-1}$, por $24 \mathrm{~h}$, enquanto que no Laboratório de Geocronologia da USP, $100 \mathrm{mg}$ de amostra foram lixiviados com uma solução mista de $\mathrm{HCl} 3 \mathrm{~mol} \mathrm{~L}^{-1}+\mathrm{HNO}_{3} 3,5 \mathrm{~mol} \mathrm{~L}-1$, aquecida por 30 min a $100{ }^{\circ} \mathrm{C}$.

A separação cromatográfica do $\mathrm{Pb}$ foi realizada em meio $\mathrm{HBr}$ e $\mathrm{HCl}$, com resina de troca iônica (Biorad AG1 $8^{\circledR}{ }^{\circledR}, 200-400$ mesh) em microcolunas de Teflon. $\mathrm{O} \mathrm{Pb}$ purificado foi concentrado com $\mathrm{H}_{3} \mathrm{PO}_{4}$ e depositado em filamento Rênio (Re) purificado, junto com sílica 
gel, para posterior análise isotópica por espectrometria de massa de fonte por termoionização (TIMS).

No Laboratório da UFPA, foi utilizado um espectrômetro de massa de marca VG modelo ISOMASS 54E, equipado com monocoletor. $\mathrm{O}$ fator de discriminação de massa utilizado para a correção das razões isotópicas é de $0,00120 \pm 0,00030$ por u.m.a., o qual foi obtido a partir de análises repetidas de solução padrão NBS 982. No laboratório da USP, as composições isotópicas do $\mathrm{Pb}$ também foram determinadas com um espectrômetro de massa de marca VG modelo 354 equipado com multicoletores, sendo as composições isotópicas corrigidas para fracionamento isotópico de $0,11 \%$ por u.m.a para as razões ${ }^{206} \mathrm{~Pb} /{ }^{204} \mathrm{~Pb},{ }^{207} \mathrm{~Pb} /{ }^{204} \mathrm{~Pb}$, enquanto que as razões ${ }^{208} \mathrm{~Pb} /{ }^{204} \mathrm{~Pb}$ foram corrigidas com um fator de $0,07 \%$ por u.m.a, com base em valores obtidos para o padrão NBS 981, analisado em condições similares. Foram realizados brancos de $\mathrm{Pb}$ para monitorar o nível de contaminação introduzida durante os procedimentos analíticos habituais para obtenção dos dados isotópicos.

\section{RESULTADOS}

\section{Composição mineralógica}

As 23 amostras coletadas nas margens esquerda e direita do Rio Guamá apresentaram composição mineralógica muito homogênea. A fração fina do sedimento $(<63 \mu \mathrm{m})$ é composta fundamentalmente de quartzo, microclínio e argilominerais do tipo esmectita, illita e caulinita, sendo semelhante à=composição mineralógica previamente encontrada nas amostras da Baía do Guajará. ${ }^{11}$

\section{Teores de $\mathrm{Pb}, \mathrm{Fe}, \mathrm{Mg}$, Fe e matéria orgânica dos sedimentos do Rio Guamá}

Os teores de $\mathrm{Pb}$, assim como os teores de $\mathrm{Al}, \mathrm{Mg}$ e Fe, e a percentagem de matéria orgânica da fração fina das amostras de sedimentos do Rio Guamá estão apresentados na Tabela 1 e a distribuição das concentrações de $\mathrm{Pb}$ ao longo das margens direita e esquerda está apresentada na Figura 1.

As concentrações de $\mathrm{Pb}$ em ambas as margens do Rio Guamá foram praticamente similares, com valores médios de 15,8 e 18,1 mg $\mathrm{kg}^{-1}$ para as margens esquerda e direita, respectivamente.

Para a margem esquerda do Rio Guamá, as amostras apresentam uma distribuição de concentrações homogênea, comprovada pelo valor baixo de desvio padrão $( \pm 1,5)$. $\mathrm{O} \mathrm{Pb}$ das amostras de sedimentos coletadas ao longo da margem esquerda do rio do lado norte das Ilhas de Cumbu e Grande apresenta uma leve tendência com diminuição das concentrações de montante para jusante. As amostras do lado sul das Ilhas, contudo, apresentam teores praticamente constantes.

Para os sedimentos coletados na margem direita do Rio Guamá, o Pb mostra a mesma tendência que para as amostras da margem esquerda ao lado norte das Ilhas, com uma leve diminuição dos teores em direção à Baía de Guajará. Entretanto, as concentrações de $\mathrm{Pb}$ apresentam variações importantes nas amostras localizadas nas proximidades do Rio Aurá, evidenciadas pelo alto desvio padrão ( \pm 4,7). Sendo assim, apesar das médias entre as margens esquerda e direita serem muito parecidas, as concentrações de $\mathrm{Pb}$ nas amostras da margem direita não apresentam a homogeneidade evidenciada nas da margem esquerda.

Assim como para o $\mathrm{Pb}$, os elementos $\mathrm{Al}, \mathrm{Fe}$ e $\mathrm{Mg}$ apresentaram concentrações médias similares em ambas as margens porém, novamente, a distribuição é muito mais homogênea na margem esquerda, com desvios padrão de $\pm 0,57, \pm 0,04 \mathrm{e} \pm 0,28$, do que na margem direita com desvios padrão de $\pm 1,73, \pm 0,12 \mathrm{e} \pm 1,04$, respectivamente para Al, Fe e Mg (Tabela 1).
Tabela 1. Concentração de $\mathrm{Pb}$ e porcentagem de matéria orgânica (MO) das amostras de sedimentos coletadas nas margens direita e esquerda do Rio Guamá (concentrações expressas em $\mathrm{mg} \mathrm{kg}^{-1}$ para $\mathrm{Pb}$ e em \%-peso para $\mathrm{Al}$, $\mathrm{Fe}, \mathrm{Mg}$ e MO). IC: Ilha do Cumbu; IG: Ilha Grande; C: continente

\begin{tabular}{|c|c|c|c|c|c|c|}
\hline & \multirow[t]{2}{*}{ Amostras } & \multicolumn{5}{|c|}{ Elementos químicos e matéria orgânica } \\
\hline & & $\begin{array}{c}\mathrm{Pb} \\
\left(\mathrm{mg} \mathrm{kg}^{-1}\right)\end{array}$ & $\begin{array}{c}\mathrm{Al} \\
(\%)\end{array}$ & $\begin{array}{l}\mathrm{Fe} \\
(\%)\end{array}$ & $\begin{array}{l}\mathrm{Mg} \\
(\%)\end{array}$ & $\begin{array}{l}\mathrm{MO} \\
(\%)\end{array}$ \\
\hline \multirow{11}{*}{$\begin{array}{l}\text { Margem direita } \\
\text { do Rio Guamá }\end{array}$} & Pt.01 & 22,6 & 7,45 & 0,51 & 4,39 & 12 \\
\hline & Pt.02 & 19,5 & 4,90 & 0,42 & 3,12 & 10 \\
\hline & Pt.03 & 15,6 & 4,70 & 0,37 & 2,55 & 11 \\
\hline & Pt.04 & 10,8 & 2,43 & 0,19 & 1,46 & 5 \\
\hline & Pt.05 & 10,8 & 2,73 & 0,21 & 1,37 & 5 \\
\hline & Pt.06 & 21,2 & 6,47 & 0,47 & 3,42 & 12 \\
\hline & Pt.07 & 12,6 & 3,29 & 0,27 & 1,89 & 9 \\
\hline & Pt.08 & 11,2 & 3,09 & 0,23 & 1,57 & 9 \\
\hline & Pt.09 & 17,5 & 4,99 & 0,36 & 3,04 & 11 \\
\hline & Média & 15,8 & 4,45 & 0,34 & 2,53 & 9,3 \\
\hline & $\begin{array}{l}\text { Desvio } \\
\text { padrão }\end{array}$ & 4,7 & 1,73 & 0,12 & 1,04 & 2,7 \\
\hline \multirow{16}{*}{$\begin{array}{l}\text { Margem esquerda } \\
\text { do Rio Guamá }\end{array}$} & IC.01 & 15,8 & 3,44 & 0,29 & 1,99 & 7 \\
\hline & IC.02 & 19,6 & 4,92 & 0,42 & 2,79 & 9 \\
\hline & IC.03 & 18,8 & 4,72 & 0,38 & 2,57 & 5 \\
\hline & C. 04 & 20,4 & 5,46 & 0,43 & 2,41 & 10 \\
\hline & IG.05 & 18,5 & 4,87 & 0,39 & 2,80 & 7 \\
\hline & IG.06 & 16,3 & 3,65 & 0,30 & 2,26 & 8 \\
\hline & С.07 & 18,3 & 4,34 & 0,35 & 2,51 & 8 \\
\hline & C. 08 & 18,0 & 4,36 & 0,34 & 2,35 & 14 \\
\hline & С.09 & 19,9 & 4,84 & 0,37 & 2,58 & 7 \\
\hline & IG.10 & 16,7 & 3,84 & 0,31 & 2,20 & 7 \\
\hline & IG.11 & 19,5 & 4,54 & 0,36 & 2,97 & 12 \\
\hline & IC. 12 & 18,3 & 4,40 & 0,35 & 2,71 & 8 \\
\hline & IC.13 & 16,3 & 4,49 & 0,33 & 2,30 & 7 \\
\hline & IC. 14 & 16,6 & 3,71 & 0,31 & 2,18 & 6 \\
\hline & Média & 18,1 & 4,40 & 0,35 & 2,47 & 8,2 \\
\hline & $\begin{array}{l}\text { Desvio } \\
\text { padrão }\end{array}$ & 1,50 & 0,57 & 0,04 & 0,28 & 2,40 \\
\hline
\end{tabular}

Diferentemente do comportamento observado para os metais, a matéria orgânica apresenta concentrações nos sedimentos de ambas as margens com a mesma ordem de grandeza. $\mathrm{O}$ valor médio observado para a margem direita $(\mathrm{MO}=9,3 \%$, desvio padrão $\pm 2,4)$ é um pouco maior que aquele apresentado pela margem esquerda $(\mathrm{MO}=8,2 \%$, desvio padrão $= \pm 2,7$ ).

Os coeficientes de correlação dos teores de $\mathrm{Pb}$ com a matéria orgânica e com os teores de $\mathrm{Al}, \mathrm{Fe}$ e $\mathrm{Mg}$, determinados com auxílio do programa Estatística ${ }^{\circledR}$ são apresentados na Tabela 2. Apesar das variações observadas na distribuição das concentrações, todas as amostras da margem direita mostraram excelentes correlações de $\mathrm{Pb}$ com $\mathrm{Al}, \mathrm{Mg}$ e $\mathrm{Fe}$ (coeficientes de correlação $\geq 0,97$ ) e boa com a matéria orgânica (coeficiente de correlação $=0,83$ ). Nas amostras da margem esquerda, os teores de $\mathrm{Pb}$ apresentaram correlações excelentes com Al, Mg e Fe (coeficiente de correlação $\geq 0,94$ ), porém não há correlação com a matéria orgânica (coeficiente de correlação $=0,24)$. 


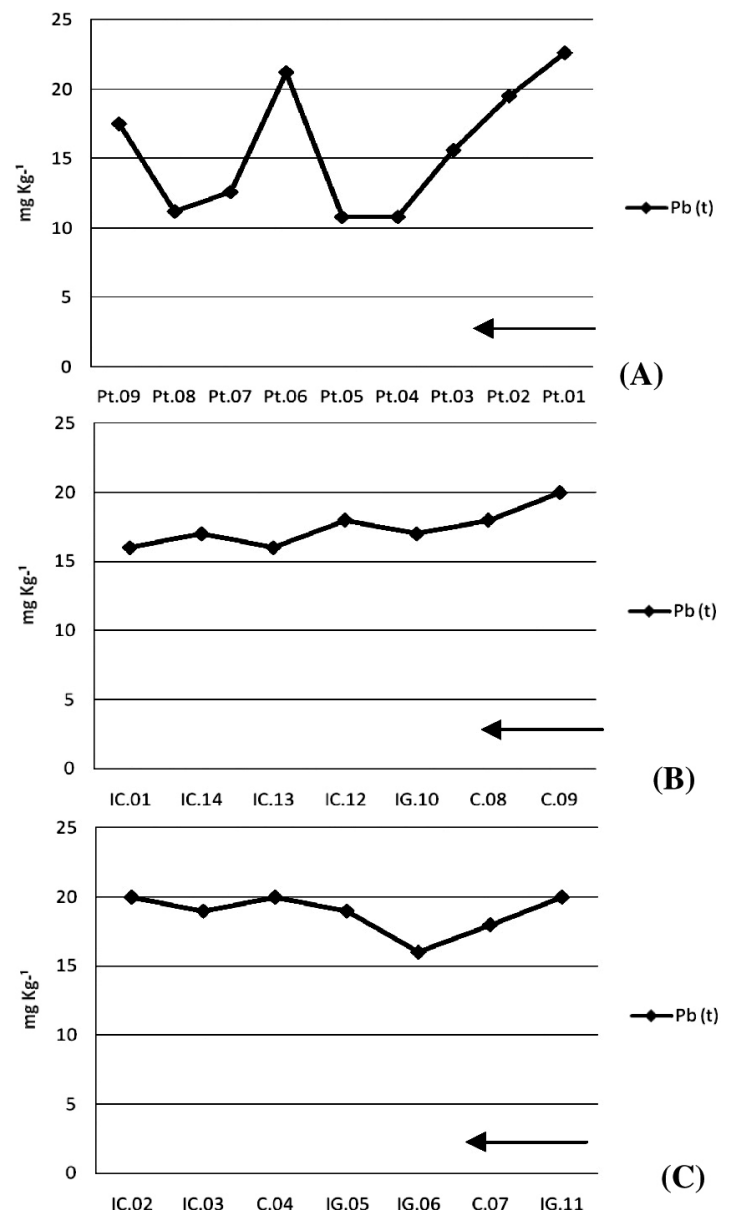

Figura 1. Distribuição das concentrações totais de Pb das margens do Rio Guamá: (A) margem direita; (B) margem esquerda, lado norte das ilhas; (C) margem esquerda, lado sul das ilhas. A seta indica o sentido da corrente

\section{Geocronologia ${ }^{210} \mathrm{~Pb}$ dos sedimentos do Rio Guamá e da Baía do Guajará}

Foram coletados 3 testemunhos de sedimento de fundo com aproximadamente $50 \mathrm{~cm}$ de comprimento, 2 do Rio Guamá (C.08 e IC.03) e um da Baía do Guajará (IJa-01). Os sedimentos foram coletados em 2006 com auxílio de um testemunhador do tipo russian peat borer ${ }^{21}$ e cortados em fatias de $5 \mathrm{~cm}$ de espessura. Os resultados são apresentados na Tabela 3 .
Tabela 2. Valores do coeficiente de correlação entre concentração total de $\mathrm{Pb}$ e matéria orgânica (MO), $\mathrm{Al}, \mathrm{Fe}$ e $\mathrm{Mg}$, respectivamente

\begin{tabular}{lcccc}
\hline Margens & M.O & $\mathrm{Al}$ & $\mathrm{Mg}$ & $\mathrm{Fe}$ \\
\hline Direita & 0,83 & 0,97 & 0,99 & 0,99 \\
Esquerda & 0,24 & 0,95 & 0,97 & 0,94 \\
\hline
\end{tabular}

Para o testemunho do Rio Guamá localizado atrás da Ilha de Cumbu (amostra IC.03), 9 fatias forneceram um registro histórico dos últimos 63 anos e permitiram estimar uma velocidade média de sedimentação de $0,59 \mathrm{~cm} /$ ano. Para o outro testemunho de sedimento da margem esquerda do Rio Guamá (amostra C.08), a datação ${ }^{210} \mathrm{~Pb}$ de 7 fatias permitiu voltar aos últimos 65 anos e forneceu uma velocidade média de sedimentação um pouco menor de $0,56 \mathrm{~cm} / \mathrm{ano}$. Os dados ${ }^{210} \mathrm{~Pb}$ de 5 fatias do testemunho da Ilha Jararaca, na Baía do Guajará (amostra IJa-01) forneceram um intervalo de tempo de 43 anos e uma velocidade média de sedimentação mais alta, de $0,70 \mathrm{~cm} / \mathrm{ano}$. Esses resultados indicam que os dados geoquímicos e isotópicos obtidos nesse trabalho com as amostras coletadas com a draga de Petersen representam um registro histórico dos últimos 8-9 anos para o Rio Guamá e dos últimos 7 anos para a Baía de Guajará.

\section{Dados isotópicos de Pb dos sedimentos do Rio Guamá e da Baia do Guajará}

As razões isotópicas de $\mathrm{Pb}$ determinadas em 21 amostras de sedimentos de fundo do Rio Guamá e 10 amostras de sedimentos da Baía do Guajará, junto com as concentrações totais de $\mathrm{Pb}$ estão apresentados na Tabela 4. As amostras do Rio Guamá apresentaram baixas concentrações médias de $\mathrm{Pb}$, variando entre $16-18 \mathrm{mg} \mathrm{kg}^{-1} \mathrm{e}$ uma composição isotópica variando entre 1,193 a 1,200 para a razão ${ }^{206} \mathrm{~Pb} /{ }^{207} \mathrm{~Pb}$. Alguns pontos da margem direita do rio distinguem-se com concentração de $\mathrm{Pb}\left(11-13 \mathrm{mg} \mathrm{kg}^{-1}\right)$ e composições isotópicas $\left(1,186<{ }^{206} \mathrm{~Pb} /{ }^{207} \mathrm{~Pb}<1,192\right)$ menores.

Na Baía do Guajará, as concentrações de Pb são maiores (28 a 46 mg $\left.\mathrm{kg}^{-1}\right)$ e as razões ${ }^{206} \mathrm{~Pb} /{ }^{207} \mathrm{~Pb}$ apresentam variações maiores e valores mais baixos em relação às amostras do Rio Guamá, definindo um intervalo entre $1,172-1,188$. O menor valor de razão ${ }^{206} \mathrm{~Pb} /{ }^{207} \mathrm{~Pb}$ foi encontrado na amostra C.V.C, a única localizada na orla de Belém, na margem direita da baía, próximo a um canal de lançamento de esgoto in natura.

Os resultados isotópicos foram lançados em um diagrama de razões isotópicas ${ }^{206} \mathrm{~Pb} /{ }^{207} \mathrm{~Pb}$ vs concentração do metal $\mathrm{Pb}$ dos sedimentos de fundo do Rio Guamá e da Baía do Guajará, incluindo também os dados de uma amostra proveniente do Rio Mocajatuba, ${ }^{12}$ localizado no setor nordeste da área metropolitana

Tabela 3. Resultados de ${ }^{210} \mathrm{~Pb}$ para os testemunhos de sedimentos de fundo do Rio Guamá (amostras C.08 e IC.03) e da Baía do Guajará (amostra I.Ja-01) Data inicial 2006

\begin{tabular}{|c|c|c|c|c|c|c|c|c|}
\hline \multicolumn{3}{|c|}{$\begin{array}{l}\text { Baía do Guajará } \\
\text { Amostra I.Ja-01 }\end{array}$} & \multicolumn{3}{|c|}{$\begin{array}{c}\text { Rio Guamá (margem esquerda) } \\
\text { Amostra C.08 }\end{array}$} & \multicolumn{3}{|c|}{$\begin{array}{c}\text { Rio Guamá (Ilha do Cumbu) } \\
\text { Amostra IC.03 }\end{array}$} \\
\hline $\begin{array}{l}\text { Profundidade } \\
\text { corrigida }(\mathrm{cm})\end{array}$ & $\begin{array}{l}\text { Idade } \\
\text { (anos) }\end{array}$ & Data & $\begin{array}{l}\text { Profundidade } \\
\text { corrigida }(\mathrm{cm})\end{array}$ & $\begin{array}{l}\text { Idade } \\
\text { (anos) }\end{array}$ & Data & $\begin{array}{l}\text { Profundidade } \\
\text { corrigida }(\mathrm{cm})\end{array}$ & $\begin{array}{l}\text { Idade } \\
(\text { anos })\end{array}$ & Data \\
\hline 10 & 14 & 1992 & 5 & 9 & 1997 & 4 & 7 & 1999 \\
\hline 15 & 21 & 1985 & 10 & 18 & 1988 & 8 & 13 & 1993 \\
\hline 20 & 28 & 1978 & 16 & 28 & 1978 & 12 & 20 & 1986 \\
\hline 25 & 35 & 1970 & 22 & 38 & 1968 & 16 & 27 & 1979 \\
\hline \multirow[t]{5}{*}{30} & 43 & 1963 & 27 & 47 & 1959 & 20 & 33 & 1973 \\
\hline & & & 32 & 57 & 1949 & 24 & 40 & 1966 \\
\hline & & & 37 & 65 & 1941 & 28 & 48 & 1960 \\
\hline & & & & & & 33 & 55 & 1955 \\
\hline & & & & & & 38 & 63 & 1949 \\
\hline
\end{tabular}


Tabela 4. Razões isotópicas de Pb da fração fina dos sedimentos de fundo do Rio Guamá e da Baía do Guajará

\begin{tabular}{|c|c|c|c|c|c|c|c|c|c|}
\hline \multicolumn{10}{|c|}{ Margem esquerda do Rio Guamá } \\
\hline Amostras & $\mathrm{Pb}$ mg kg- ${ }^{1}$ & ${ }^{206} \mathrm{~Pb} /{ }^{204} \mathrm{~Pb}$ & Erro $\%(1 \sigma)$ & ${ }^{207} \mathrm{~Pb} /{ }^{204} \mathrm{~Pb}$ & Erro $\%(1 \sigma)$ & ${ }^{208} \mathrm{~Pb} /{ }^{204} \mathrm{~Pb}$ & Erro $\%(1 \sigma)$ & ${ }^{206} \mathrm{~Pb} /{ }^{207} \mathrm{~Pb}$ & Erro $\%(1 \sigma)$ \\
\hline IC.01 & 15,8 & 18,807 & 0,003 & 15,674 & 0,003 & 39,000 & 0,003 & 1,200 & 0,001 \\
\hline IC.02 & 19,6 & 18,742 & 0,008 & 15,690 & 0,007 & 38,883 & 0,007 & 1,195 & 0,002 \\
\hline IC.03 & 18,8 & 18,760 & 0,007 & 15,683 & 0,008 & 38,831 & 0,008 & 1,196 & 0,001 \\
\hline C.04 & 20,4 & 18,696 & 0,009 & 15,668 & 0,010 & 38,737 & 0,009 & 1,193 & 0,003 \\
\hline IG.05 & 18,5 & 18,782 & 0,008 & 15,720 & 0,008 & 38,974 & 0,007 & 1,195 & 0,003 \\
\hline IG.06 & 16,3 & 18,781 & 0,007 & 15,700 & 0,008 & 38,933 & 0,007 & 1,196 & 0,002 \\
\hline C. 07 & 18,3 & 18,843 & 0,006 & 15,698 & 0,005 & 39,033 & 0,005 & 1,200 & 0,002 \\
\hline C. 08 & 18,0 & 18,817 & 0,014 & 15,714 & 0,015 & 39,085 & 0,014 & 1,197 & 0,004 \\
\hline C.09 & 19,9 & 18,802 & 0,006 & 15,724 & 0,007 & 39,012 & 0,008 & 1,196 & 0,002 \\
\hline IG.11 & 19,5 & 18,793 & 0,011 & 15,704 & 0,011 & 38,952 & 0,010 & 1,197 & 0,002 \\
\hline IC. 12 & 18,3 & 18,771 & 0,011 & 15,713 & 0,011 & 38,968 & 0,011 & 1,195 & 0,004 \\
\hline IC. 14 & 16,6 & 18,756 & 0,007 & 15,685 & 0,007 & 38,891 & 0,007 & 1,196 & 0,002 \\
\hline \multicolumn{10}{|c|}{ Margem direita do Rio Guamá } \\
\hline Amostras & $\mathrm{Pb}$ mg kg-1 & ${ }^{206} \mathrm{~Pb} /{ }^{204} \mathrm{~Pb}$ & Erro $\%(1 \sigma)$ & ${ }^{207} \mathrm{~Pb} /{ }^{204} \mathrm{~Pb}$ & Erro $\%(1 \sigma)$ & ${ }^{208} \mathrm{~Pb} /{ }^{204} \mathrm{~Pb}$ & Erro $\%(1 \sigma)$ & ${ }^{206} \mathrm{~Pb} /{ }^{207} \mathrm{~Pb}$ & Erro $\%(1 \sigma)$ \\
\hline Pt.01 & 22,6 & 18,879 & 0,062 & 15,772 & 0,090 & 39,127 & 0,120 & 1,197 & 0,031 \\
\hline Pt.02 & 19,5 & 18,780 & 0,061 & 15,734 & 0,094 & 38,996 & 0,127 & 1,194 & 0,030 \\
\hline Pt.03 & 15,6 & 18,842 & 0,072 & 15,773 & 0,102 & 39,126 & 0,127 & 1,195 & 0,035 \\
\hline Pt.04 & 10,8 & 18,738 & 0,061 & 15,723 & 0,091 & 38,906 & 0,120 & 1,192 & 0,030 \\
\hline Pt.05 & 10,8 & 18,657 & 0,060 & 15,726 & 0,089 & 38,902 & 0,119 & 1,186 & 0,030 \\
\hline Pt.06 & 21,2 & 18,841 & 0,061 & 15,742 & 0,091 & 39,034 & 0,121 & 1,197 & 0,030 \\
\hline Pt.07 & 12,6 & 18,684 & 0,068 & 15,758 & 0,095 & 38,948 & 0,126 & 1,186 & 0,034 \\
\hline Pt.08 & 11,2 & 18,751 & 0,061 & 15,728 & 0,092 & 38,956 & 0,122 & 1,192 & 0,030 \\
\hline Pt.09 & 17,5 & 18,876 & 0,064 & 15,771 & 0,094 & 39,147 & 0,122 & 1,197 & 0,032 \\
\hline \multicolumn{10}{|c|}{ Baía do Guajará } \\
\hline Amostras & $\mathrm{Pb}$ mg kg-1 & ${ }^{206} \mathrm{~Pb} /{ }^{204} \mathrm{~Pb}$ & Erro $\%(1 \sigma)$ & ${ }^{207} \mathrm{~Pb} /{ }^{204} \mathrm{~Pb}$ & Erro $\%(1 \sigma)$ & ${ }^{208} \mathrm{~Pb} /{ }^{204} \mathrm{~Pb}$ & Erro $\%(1 \sigma)$ & ${ }^{206} \mathrm{~Pb} /{ }^{207} \mathrm{~Pb}$ & Erro $\%(1 \sigma)$ \\
\hline IO-01 & 30,0 & 18,464 & 0,006 & 15,652 & 0,006 & 38,487 & 0,006 & 1,180 & 0,003 \\
\hline IO-02 & 46,2 & 18,414 & 0,005 & 15,703 & 0,005 & 38,527 & 0,006 & 1,173 & 0,002 \\
\hline IO-03 & 29,2 & 18,403 & 0,005 & 15,661 & 0,007 & 38,430 & 0,007 & 1,175 & 0,002 \\
\hline IO-04 & 28,3 & 18,621 & 0,006 & 15,668 & 0,006 & 38,657 & 0,006 & 1,188 & 0,001 \\
\hline IO-05 & 35,8 & 18,515 & 0,010 & 15,673 & 0,012 & 38,540 & 0,009 & 1,181 & 0,002 \\
\hline IO-06 & 36,0 & 18,410 & 0,013 & 15,650 & 0,013 & 38,381 & 0,012 & 1,176 & 0,007 \\
\hline I.Ja-01 & 42,9 & 18,487 & 0,004 & 15,662 & 0,004 & 38,523 & 0,004 & 1,180 & 0,002 \\
\hline I.Mi-01 & 39,5 & 18,614 & 0,004 & 15,665 & 0,004 & 38,635 & 0,004 & 1,188 & 0,001 \\
\hline I.Ju-01 & 31,1 & 18,592 & 0,005 & 15,676 & 0,006 & 38,630 & 0,006 & 1,186 & 0,002 \\
\hline C.V.C & 36,8 & 18,311 & 0,006 & 15,628 & 0,007 & 38,262 & 0,007 & 1,172 & 0,002 \\
\hline
\end{tabular}

de Belém, próximo da BR 316, principal via de acesso à cidade, onde a produção de efluentes industriais é elevada (Figura 2). ${ }^{12}$ Nesse diagrama, os pontos se distribuem em dois grupos distintos, que foram identificados de acordo com a localização geográfica. $\mathrm{O}$ primeiro grupo corresponde às amostras das margens do Rio Guamá e o segundo, às amostras da Baía do Guajará. Valores anômalos foram encontrados em algumas amostras do primeiro grupo, na margem direita do rio.

As amostras do primeiro grupo apresentam razões isotópicas ${ }^{206} \mathrm{~Pb} /{ }^{207} \mathrm{~Pb}$ homogêneas entre $1,194-1,200$, junto com concentrações baixas de $\mathrm{Pb}$, sem grande variação (16 a $23 \mathrm{mg} \mathrm{kg}^{-1}$ ). Os pontos definem, portanto, um campo bastante homogêneo e restrito para os sedimentos do Rio Guamá, sobretudo aqueles da margem esquerda.
Na margem direita, os quatro pontos Pt.04, Pt.05, Pt.07 e Pt.08, que apresentam valores anômalos com razões ${ }^{206} \mathrm{~Pb} /{ }^{207} \mathrm{~Pb}$ mais baixas, no intervalo de 1,186-1,192, estão localizados próximos da desembocadura do Rio Aurá. Esses pontos mostraram, também, teores de $\mathrm{Pb}$ significativamente mais baixos de $11 \mathrm{mg} \mathrm{kg}^{-1}$ (Pt.04, Pt.05 e Pt.08) a $13 \mathrm{mg} \mathrm{kg}^{-1}$ (Pt.07), em relação ao conjunto de amostras do Rio Guamá.

As amostras do segundo grupo definiram um campo nitidamente distinto do primeiro, com maiores variações de teores e composições isotópicas de $\mathrm{Pb}$. O diagrama evidencia uma correlação negativa entre as concentrações de $\mathrm{Pb}$ que aumentam de 28 a $46 \mathrm{mg} \mathrm{kg}^{-1}$ e as razões isotópicas ${ }^{206} \mathrm{~Pb} /{ }^{207} \mathrm{~Pb}$ que diminuem de 1,188 a 1,172 . Os pontos tendem a se deslocar na direção da amostra do Rio Mocajatuba, a 
qual apresenta teor de $\mathrm{Pb}$ de $89 \mathrm{mg} \mathrm{kg}^{-1}$, com razão ${ }^{206} \mathrm{~Pb} /{ }^{207} \mathrm{~Pb}$ de 1,162 (Figura 2).

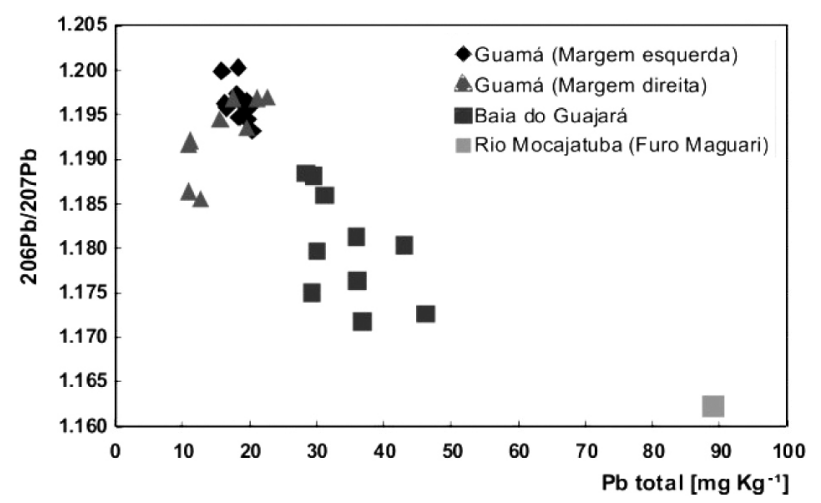

Figura 2. Diagrama de razão isotópica $\left({ }^{206} \mathrm{~Pb} /{ }^{207} \mathrm{~Pb}\right)$ vs concentração de $\mathrm{Pb}$ $\left(m g \mathrm{~kg}^{-1}\right)$, para a fração fina dos sedimentos de fundo da foz do Rio Guamá e da Baía do Guajará, junto com a amostra de sedimento do Rio Mocajatuba

\section{DISCUSSÃO}

\section{Distribuição do $\mathbf{P b}$}

A relativa homogeneidade das concentrações de $\mathrm{Pb}$ dos sedimentos da margem esquerda do Rio Guamá deve retratar a distribuição natural dos metais pesados no ambiente sem influência antropogênica. O comportamento distinto das concentrações ao longo do rio na direção da baía, entre as amostras coletadas no curso principal do rio, do lado norte das Ilhas do Cumbú e Grande, e as amostras coletadas a sul das ilhas, deve estar relacionado a diferenças no regime hidrodinâmico do Rio Guamá e reflete, provavelmente, os efeitos conjugados da maré com a correnteza do rio. O elevado valor médio de $\mathrm{Pb}$ de $54,5 \mathrm{mg} \mathrm{kg}^{-1}$, observado anteriormente na fração fina de sedimentos das proximidades da Ilha do Cumbú, ${ }^{10}$ não foi confirmado por esse estudo, que forneceu, ao contrário, um valor médio de 18,1 $\pm 1,5 \mathrm{mg}$ $\mathrm{kg}^{-1}$ coerentemente inferior ao observado na Baía de Guajará (33,3 e $\left.38,3 \mathrm{mg} \mathrm{kg}^{-1}\right){ }^{10,11}$

A concentração média de $\mathrm{Pb}\left(15,8 \pm 4,7 \mathrm{mg} \mathrm{kg}^{-1}\right)$ dos sedimentos coletados na margem direita do Rio Guamá é similar à da outra margem. Porém, a diferença com a margem esquerda reside na oscilação das concentrações de $\mathrm{Pb}$ no rio, abaixo e acima da confluência com o Rio Aurá (ponto Pt.05). Essa variação indica a interferência local desse tributário sobre o padrão de distribuição de concentração dos metais relacionados ao fluxo natural do Rio Guamá. Uma contribuição do Rio Aurá no balanço de concentração de metais pesados nas amostras da margem direita não deve ser descartada, já que esse rio recebe quantidades significativas de chorume, resultante da decomposição do depósito de lixo de Belém. ${ }^{22}$

Nos sedimentos da margem esquerda do Rio Guamá, a matéria orgânica não tem um papel significativo na complexação do $\mathrm{Pb}$, tendo em vista a ausência de correlação $(r=0,24)$. Por outro lado, as excelentes correlações com $\mathrm{Al}$ e $\mathrm{Mg}(0,94<\mathrm{r}<0,97)$ indicam que devem também estar adsorvidos nas estruturas dos argilominerais, já que o Mg é comum em minerais do grupo das esmectitas, um dos argilominerais presentes nas amostras analisadas. Além disso, o Pb deve provavelmente estar também associado a oxi-hidróxidos de ferro, de acordo com a excelente correlação com $\mathrm{Fe}(\mathrm{r}=0,94)$.

$\mathrm{Na}$ margem direita, as excelentes correlações com $\mathrm{Al}, \mathrm{Mg}$ e Fe $(0,97<\mathrm{r}<0,99)$ indicam também que o $\mathrm{Pb}$ é adsorvido principalmente nas estruturas dos argilominerais e, provavelmente, em oxi-hidróxidos de ferro. Além disso, a boa correlação entre matéria orgânica $(r=0,83)$ e teor de $\mathrm{Pb}$ indica que a matéria orgânica teve um papel relevante na complexação do metal. Esses resultados são compatíveis com vários estudos realizados em sedimentos. ${ }^{23,24}$

A redistribuição dos teores de $\mathrm{Pb}$, localizadamente, nos arredores da desembocadura do Rio Aurá é aparentemente provocada por processos hidrodinâmicos na área de confluência entre os Rios Guamá e Aurá. O aumento localizado de teores de $\mathrm{Pb}$ no ponto de amostragem Pt.06 pode estar relacionado à quantidade de matéria orgânica superior (12\%) comparativamente aos demais pontos vizinhos (5-9\%), ressaltando as boas correlações desse elemento com a matéria orgânica.

\section{Assinatura isotópica de $\mathbf{P b}$}

A assinatura isotópica de $\mathrm{Pb}$ ambiental de origem natural em sedimentos de fundo pode variar significativamente, em função das características geológicas regionais, e é preciso determinar essa assinatura em um determinado ambiente para poder identificar as possíveis contribuições antropogênicas com base na composição isotópica.

As amostras de sedimentos da margem esquerda do Rio Guamá forneceram teor e composição isotópica de $\mathrm{Pb}$ bastante homogêneas e constantes. Como essa área é preservada com bastante vegetação e sem evidência de influência antrópica, a concentração média em torno de $18 \mathrm{mg} \mathrm{kg}^{-1}$ do $\mathrm{Pb}$ dessas amostras pode ser considerada como representativa do background geogênico desse metal para o sistema hidrográfico de Belém, sendo compatível com os dados da literatura concernentes aos teores nos sedimentos argilosos. ${ }^{25,26} \mathrm{Da}$ mesma forma, o valor médio de $1,196 \pm 0,002$ pode ser considerado com referência para a razão ${ }^{206} \mathrm{~Pb} /{ }^{207} \mathrm{~Pb}$ do $\mathrm{Pb}$ natural do sistema hidrográfico de Belém. Na região de Belém, estudos anteriores apontaram valores similar para o $\mathrm{Pb}$ natural $\left({ }^{206} \mathrm{~Pb} /{ }^{207} \mathrm{~Pb} \approx 1,20\right)$, obtidos em amostras de sedimentos do Rio Guamá e de diversos locais do sistema hidrográfico considerados como isentos de contribuição antropogênica. ${ }^{12}=$

Na margem direita do Rio Guamá, a maioria das amostras apresentou valores de $\mathrm{Pb}$ parecidos com os dados da margem esquerda em termos de concentração (15,6-22,6 mg kg ${ }^{-1}$ de $\mathrm{Pb}$ ) e composição isotópica $\left(1,194<{ }^{206} \mathrm{~Pb} /{ }^{207} \mathrm{~Pb}<1,197\right)$. Os valores mais baixos nos teores de $\mathrm{Pb}$ e nas razões ${ }^{206} \mathrm{~Pb} /{ }^{207} \mathrm{~Pb}$, detectados em 4 pontos de amostragem, representam valores anômalos bastante localizados, tendo em vista a escala de amostragem ( $1 \mathrm{~km}$ de espaçamento) bem menor que aquela da margem esquerda do rio ( $2 \mathrm{~km}$ de espaçamento). Um ponto surpreendente é o fato dessas amostras apresentarem valores mais baixos de razões isotópicas de $\mathrm{Pb}$ no intervalo de 1,192 a 1,186, apesar dos valores de $\mathrm{Pb}$ serem menores do que a média do teor de $\mathrm{Pb}$ natural, definido com base nos dados da margem esquerda.

Valores de razões isotópicas ${ }^{206} \mathrm{~Pb} /{ }^{207} \mathrm{~Pb}$ mais baixos são geralmente indicadores de influência antrópica, ${ }^{6,27,28}$ que tende a reduzir as razões isotópicas de $\mathrm{Pb}$ natural quando há mistura com $\mathrm{Pb}$ antropogênico. Dessa forma, os dados encontrados nas amostras Pt.04, Pt.05, Pt.07 e Pt.08 indicam uma assinatura isotópica mais antropogênica que as médias apresentadas pelos sedimentos de fundo do Rio Guamá. Entretanto, ao contrário das demais, mostram uma redução nos teores de $\mathrm{Pb}$.

Uma possível interpretação para explicar essa discrepância observada na foz do Rio Aurá seria através das mudanças de pH que o Rio Aurá sofre da nascente até a foz. O chorume liberado pelo depósito de lixo homônimo possui um $\mathrm{pH}$ de 8,11, o que favorece a complexação do $\mathrm{Pb}$ em presença de abundante matéria orgânica. ${ }^{29} \mathrm{~A}$ mobilidade $\mathrm{do} \mathrm{Pb}$ é fortemente dependente do $\mathrm{pH}$. Em sedimentos com elevado conteúdo em matéria orgânica e $\mathrm{pH}$ entre 6 e $8, \mathrm{o} \mathrm{Pb}$ pode formar complexos orgânicos insolúveis, contudo, se o $\mathrm{pH}$ baixar para valores entre 4 e 6 os complexos podem se desestabilizar, liberando $\mathrm{Pb}$ para a água. ${ }^{30-31}$ Portanto, como as águas do Rio Guamá possuem características ácidas, isso contribui de forma a desestabilizar os complexos orgânicos com o $\mathrm{Pb}$, formados pela grande concentração de matéria 
orgânica e pH alcalino do chorume do depósito de lixo do Aurá. Próximo à desembocadura o $\mathrm{pH}$ da água do Rio Aurá varia bastante com o efeito da maré, com valores inferiores a 5 durante a preamar e aumentando para valores próximos a 6,5 na baixa mar. ${ }^{22}$ Esses valores de $\mathrm{pH}$ são responsáveis pela desestabilização dos complexos orgânicos contendo $\mathrm{Pb}$ reduzindo, portanto, a sua concentração, sem apagar, entretanto, a assinatura antropogênica ligada à contribuição do depósito de resíduos sólidos da região do Aurá.

Para as amostras de sedimentos coletadas na Baía do Guajará, o aumento significativo das concentrações de $\mathrm{Pb}$ em relação aos sedimentos do Rio Guamá, com valores de $\mathrm{Pb}$ total de 28,3 a 46,2 mg $\mathrm{kg}^{-1} ;^{11}$ está associado a uma diminuição das composições isotópicas de $\mathrm{Pb}$. Os valores da razão ${ }^{206} \mathrm{~Pb} /{ }^{207} \mathrm{~Pb}$ estão evoluindo de $1,186 \mathrm{a}$ 1,172 indicando, portanto, uma evolução para uma assinatura isotópica mais antropogênica. $\mathrm{O}$ valor mais baixo foi obtido para a razão ${ }^{206} \mathrm{~Pb} /{ }^{207} \mathrm{~Pb}(1,172)$ para a única amostra analisada da orla de Belém (C.V.C), enquanto que o valor mais alto $(1,186)$ foi obtido para a amostra de igarapé da Ilha das Onças (IO-04). A comparação dos dados isotópicos da Baía de Guajará com os valores encontrados em sedimentos de fundo para áreas comprovadamente contaminadas por fontes de $\mathrm{Pb}$ industriais ou domésticas como, por exemplo, a amostra de sedimento do Rio Mocajatuba ${ }^{12}\left({ }^{206} \mathrm{~Pb} /{ }^{207} \mathrm{~Pb}=1,162\right)$ ou a amostra de aerossóis coletados próximo ao distrito de Icoaraci ${ }^{4}$ onde indústrias de cerâmica, de beneficiamento de madeira, entre outras, lançam resíduos sólidos no atmosfera $\left({ }^{206} \mathrm{~Pb} /{ }^{207} \mathrm{~Pb}\right.$ de $\left.1,150 \pm 0,001\right)$, indica que as assinaturas isotópicas encontradas nos sedimentos da baía são resultados de uma mistura entre $\mathrm{Pb}$ geogênico e antropogênico.

Quando as composições isotópicas das amostras são lançadas em um diagrama ${ }^{206} \mathrm{~Pb} /{ }^{207} \mathrm{~Pb}$ vs ${ }^{206} \mathrm{~Pb} /{ }^{204} \mathrm{~Pb}$ junto com as amostras do Rio Mucajatuba e de aerossóis (Figura 3), os pontos definem um arranjo linear, o que indica uma mistura simples entre dois componentes, com razões isotópicas geogênica e antropogênica, respectivamente.

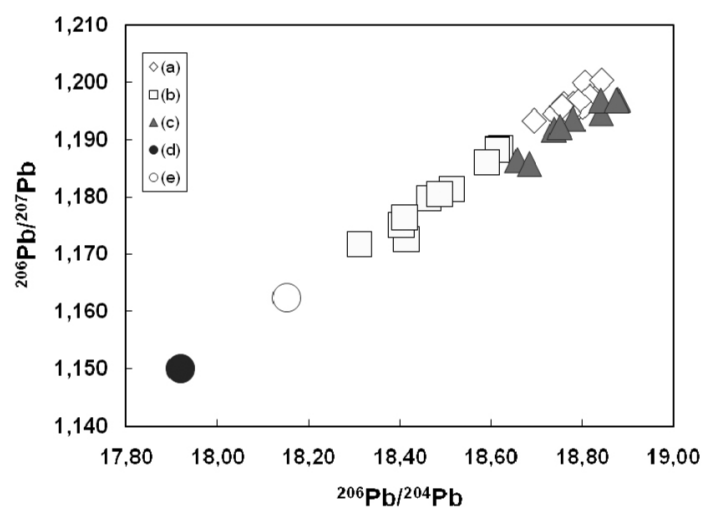

Figura 3. Diagrama de ${ }^{206} \mathrm{~Pb}{ }^{207} \mathrm{~Pb}$ vs ${ }^{206} \mathrm{~Pb} /{ }^{204} \mathrm{~Pb}$ para os sedimentos de fundo da foz do Rio Guamá e da Baía do Guajará, junto com a amostra de sedimento do rio Mucajatuba e de aerossóis do distrito de Icoaraci: (a) amostras da margem esquerda do Rio Guamá, (b) amostras da Baía do Guajará, (c) amostras da margem direita do Rio Guamá, (d) aerossóis do Distrito de Icoaraci, (e) sedimento do rio Mocajatuba

Sendo assim, é possível utilizar o modelo binário simples de mistura ${ }^{6,32}$ para quantificar de forma aproximada a contribuição antropogênica desse metal na Baía do Guajará. Para o componente geogênico foi utilizado o valor médio de 1,196 da razão ${ }^{206} \mathrm{~Pb} /{ }^{207} \mathrm{~Pb}$ (valor de referência para o background de $\mathrm{Pb}$ nos sedimentos), retirado da média das amostras da margem esquerda do Rio Guamá. Para o componente antropogênico, utilizou-se o valor de 1,150 da razão ${ }^{206} \mathrm{~Pb} /{ }^{207} \mathrm{~Pb}$ de amostras de aerossóis no distrito de Icoaraci - PA. ${ }^{4}$ Com base nesse modelo foram determinadas percentagens variando de $16 \%$ (amostra IO-04) até 51\% (amostra IO-02) nos sedimentos das ilhas e de $53 \%$ para a amostra representativa da orla de Belém (amostra CVC).

A acumulação de $\mathrm{Pb}$ de origem antropogênica encontrada em ambientes naturais, como lagos, turfeiras, geleiras, águas oceânicas, é muito mais ligada a fontes atmosféricas industriais, do que ao aporte de descargas de esgoto domésticos e industriais. ${ }^{4-6,33,34}$ Entretanto, o transporte do $\mathrm{Pb}$ através da matéria em suspensão de $\mathrm{Pb}$, tanto de origem natural quanto antropogénica, e sua acumulação nos sedimentos se torna preponderante em ambientes estuarinos. ${ }^{26}$

Na região metropolitana de Belém, o registro do menor valor de razão ${ }^{206} \mathrm{~Pb} /{ }^{207} \mathrm{~Pb}(1,150 \pm 0,001)$ foi encontrado em aerossóis do distrito de Icoaraci, no setor norte de Belém. ${ }^{4}$ Uma contribuição de $\mathrm{Pb}$ atmosférico (aerossóis), de origem antropogênica, para o $\mathrm{Pb}$ dos sedimentos de fundo da Baía do Guajará poderia explicar as assinaturas isotópicas mais baixas encontradas na região das ilhas, do outro lado da baía, mais afastada da ação antrópica tendo em vista que ventos com direção nordeste e leste repesentam cerca de $45 \%$ dos ventos em Belém (J. R. de Abreu, INMET - Belém, comunicação pessoal). Por outro lado, se os aerossóis fossem a fonte única de contaminação, seria esperada uma assinatura isotópica mais homogênea ou um gradiente de composição na baía da área mais industrializada da cidade (distrito de Icoaraci) para as áreas mais afastadas (região das ilhas), até a confluência com o Rio Guamá. Entretanto, as composições isotópicas de $\mathrm{Pb}$ nos sedimentos de fundo do furo do Maguari na desembocadura na Baía do Guajará $\left({ }^{206} \mathrm{~Pb} /{ }^{207} \mathrm{~Pb} \approx 1,196\right){ }^{12}$, ou das ilhas da baia (I.Ju-01 e I.Mi- $01 ;{ }^{206} \mathrm{~Pb} /{ }^{207} \mathrm{~Pb} \approx 1,186-1,188$; neste trabalho), mais próximas do distrito de Icoaraci, apresentam razões ${ }^{206} \mathrm{~Pb} /{ }^{207} \mathrm{~Pb}$ mais elevadas e, portanto, uma contribuição antropogênica menor. Uma possível explicação seria a proximidade da Baía do Marajó, que constitui um sistema hidrográfico em continuidade da Baía do Guajará, mais extenso e mais aberto, menos sujeito à ação antrópica, facilitando uma ampla homogeneização com o $\mathrm{Pb}$ natural. Independentemente da influência ou não da Baía de Marajó, é bastante provável que fontes de despejos in natura de efluentes domésticos e industriais também contribuam significativamente para a introdução de $\mathrm{Pb}$ antropogênico no ambiente. Quantidades elevadas desses efluentes são lançadas na orla de Belém, pelos canais de drenagem da cidade, como mostra a amostra C.V.C (Canal Val-de-Cans). Essa ação antrópica pode ter afetado a baía como um todo, através dos processos hidrodinâmicos que controlam a circulação das águas no sistema estuarino, refletindose nos sedimentos do outro lado da baía. $\mathrm{O}$ fato das mais baixas composições isotópicas nesses sedimentos terem sido encontradas no setor sul da baía $\left({ }^{206} \mathrm{~Pb} /{ }^{207} \mathrm{~Pb} \approx 1,173-1,175\right)$, onde ela é mais estreita e sofre a influência das confluências com as águas do Rio Guamá com um regime hidrodinâmico que favorece o transporte da matéria em suspensão da margem leste para a margem oeste, ${ }^{9}$ argumenta a favor dessa proposta como mecanismo principal para explicar a distribuição de $\mathrm{Pb}$ e sua composição isotópica na Baía de Guajará.

\section{CONCLUSÕES}

A distribuição das concentrações de $\mathrm{Pb}$ nos sedimentos de fundo do Rio Guamá indica um comportamento globalmente homogêneo, com teores médio de 16 a $18 \mathrm{mg} \mathrm{kg}^{-1}$. As variações de teores são controladas pelas condições hidrodinâmicas do rio, salvo algumas perturbações locais, na margem direita. Nos sedimentos, o Pb é adsorvido nas estruturas dos argilominerais (principalmente esmectita e ilita) e, provavelmente, associado a oxi-hidróxidos de ferro. A matéria orgânica foi preponderante na complexação do $\mathrm{Pb}$ apenas para os sedimentos da margem direita.

Os sedimentos de fundo do Rio Guamá apresentam também composição isotópica homogênea de $\mathrm{Pb}\left({ }^{206} \mathrm{~Pb} /{ }^{207} \mathrm{~Pb} \approx 1,195-1,20\right)$, 
sobretudo na margem esquerda do rio, similar à assinatura isotópica do $\mathrm{Pb}$ geogênico, em torno de 1,20, anteriormente apontada por Moura et al. ${ }^{12}$ para a região de Belém. A concentração média de $\mathrm{Pb}$ de $18,1 \pm$ $1,5 \mathrm{mg} \mathrm{kg}^{-1}$ dos sedimentos da margem esquerda representam o valor de background característico do Rio Guamá, isento de contribuição antropogênica com assinatura isotópica geogênica de 1,196 \pm 0,002 para a razão ${ }^{206} \mathrm{~Pb} /{ }^{207} \mathrm{~Pb}$. Na margem direita do rio, variações locais de teor de $\mathrm{Pb}$ e composições isotópicas um pouco mais antropogênicas $\left.{ }^{206} \mathrm{~Pb} /{ }^{207} \mathrm{~Pb} \approx 1,186-1,192\right)$ indicam a influência do Rio Aurá, afetado por efluentes proveniente de um aterro sanitário.

As concentrações mais elevadas associadas a uma diminuição de composição isotópica (28 $\mathrm{mg} \mathrm{kg}^{-1}<[\mathrm{Pb}]_{\text {total }}<46 \mathrm{mg} \mathrm{kg}^{-1} ; 1,173<$ ${ }^{206} \mathrm{~Pb} /{ }^{207} \mathrm{~Pb}<1,186$ ) indicam uma contribuição significativa de até $51 \%$ de $\mathrm{Pb}$ de origem antropogênica nos sedimentos de fundo da margem esquerda da Baía do Guajará. As composições isotópicas mais baixas encontradas no setor sul da baía $\left({ }^{206} \mathrm{~Pb} /{ }^{207} \mathrm{~Pb}=1,173-1,175\right)$, onde a baía é mais estreita, a similaridade com a assinatura isotópica da amostra da orla de Belém $\left({ }^{206} \mathrm{~Pb} /{ }^{207} \mathrm{~Pb}=1,172\right)$ e um regime hidrodinâmico favorável ${ }^{9}$ permitem propor um tranporte do $\mathrm{Pb}$ como material em suspensão produzido pelos efluentes domésticos e industriais dos canais de drenagem como principal mecanismo para explicar a distribuição de $\mathrm{Pb}$ e sua composição isotópica na Baía de Guajará.

\section{MATERIAL SUPLEMENTAR}

Disponível em http://quimicanova.sbq.org.br, na forma de arquivo pdf, com acesso livre.

\section{AGRADECIMENTOS}

À equipe de técnicos do Laboratório de Geologia Isotópica - ParáIso (Instituto de Geociências, UFPA), ao Centro de Pesquisas Geocronológicas - CPGeo (Instituto de Geociências, USP), ao Instituto Evandro Chagas pelo apoio na realização das análises e à agência que concedeu a bolsa (CNPq) para desenvolvimento da dissertação de mestrado, à qual este artigo faz referência.

\section{REFERÊNCIAS}

1. Simpson, S. L.; Batley, G. E.; Chariton, A. A.; Stauber, J. L.; King, C. K.; Chapman, J. C.; Hyne, R.V .; Gale, S. A.; Roach, A. C.; Maher, W. A.; Handbook for sediment quality assessment, CSIRO - Centre for environmental contaminants research, Bangor: NSW, 2005, p. 117.

2. Charlle, F. M. M.; Sci. Total Environ. 2002, 15, 121.

3. Monna, F.; Ben Othman, D.; Luck, J.M.; Sci. Total Environ. 1995, 19-34,166.

4. Bollhofer, C.F.; Rosman, K. J. R.; Geochim. Cosmochim. Acta 2000, 64, 3251.

5. Renberg, I.; Brännvall, M. L.; Bindler, R.; Emteryd, O.; Sci. Total Environ. 2002, 292, 45.

6. Komarek, M.; Ettler, V.; Chrastný, V.; Mihaljevi , M.; Environ. Int. 2008, 34,562 .
7. Pinheiro, R. V. L.; Dissertação de Mestrado, Universidade Federal do Pará, Brasil, 1987.

8. Departamento Nacional de Produção Mineral; Carta topográfica de Belém (Brasília), Escala 1:50.000, 1982.

9. Gregório, A. M. S.; Mendes, A. C.; Continental Shelf Res. 2009, 29, 609.

10. Corrêa, J. A. M.; Pereira, K. R.; Boletim do Museu Paraense Emílio Goeldi 2002, 14, 79.

11. Saraiva, A. L. L.; Dissertação de Mestrado, Universidade Federal do Pará, Brasil, 2007.

12. Moura, C. A. V.; Gaudette, H. E.; Carvalho, M. C.; Piratoba Morales, G.; Terrae 2004, 1, 16.

13. Oliveira, S. P.; Moura, C. A. V.; Rosa Filho, J. S.; $7^{\circ}$ Simpósio Sul Americano de Geologia Isotópica, Brasilia, Brasil, 2010.

14. Reynolds, R. C.; Moore, D. M.; X-ray diffraction and the analysis of clay minerals, Oxford University Press: New York, 1992, p. 332.

15. Loring, S. N.; Rantala, R. T. T.; Earth Sci. Rev. 1992, 32, 235.

16. Lima, G. M. P.; Vilas Boas, G.S .; Argollo, R. M.; Rev. Bras. Geoc. 2011, 41, 44.

17. Cazotti, R. I.; Tese de Doutorado, Universidade Federal de São Carlos, Brasil, 2003

18. Dias, F. F.; Taddei, M. H. T.; Nascimento, S. M.; Lafon, J. M.; Atoms for Peace: an International Journal 2010, 3, 26.

19. Lafon, J. M.; Rodrigues, E.; Scheller, T.; Resumos do $4^{o}$ Congresso Brasileiro de Geoquímica, Brasília, Brasil, 1993.

20. Magdaleno, G. B.; Ruiz, I. R.; Simpósio 45 Anos de Geocronologia no Brasil, São Paulo, Brasil, 2009.

21. Souza, S. R.; Oliveira, A. O.; Hartmann, C.; Gravel 2008, 6, 1.

22. Piratoba Morales, G.; Tese de Doutorado, Universidade Federal do Pará, Brasil, 2002

23. Förstner, U.; Wittman, G. T. W.; Metal pollution in the aquatic environmental, Springer: Berlin, 1983, cap. 486.

24. Solomons, W.; Förstner, U.; Metals in the hydrolocycle, Springer: Berlim, 1984, cap. 349.

25. Turekian, K. K.; Wedepohl, K. H.; Geol. Soc. Am. 1961, 72, 175.

26. Callender, E. Em Radioactive Geochronometry; Holland, H. D.; Turekian, K. K., eds.; Academic Press/Elsevier: New York, 2011, p. 463.

27. Gioia, S. M. C. L.; Pimentel, M. M.; Tessler, M.; Dantas, E. L.; Campos, J. E. G.; Guimarães, E. M.; Maruoka, M. T. S.; Nascimento, E. L. C.; Sci. Total Environ. 2006, 356, 125.

28. Kylander, M. E.; Klaminder, J.; Bindler, R.; Weiss, D. J.; Earth Planet. Sci. Lett. 2010, 290, 44.

29. Lima, L. M. Q.; Projeto de tratamento de resíduos sólidos, SESAN: Belém, 1997.

30. Department of Health and Human Services, Agency for toxic substances and disease registry; Toxicological profile for lead, Atlanta, 1993, p. 307.

31. World Health Organization; Environmental Health Criteria 165 inorganic lead, 1995, p. 300.

32. Bird, G.; Brewer, P. A.; Macklin, M. G.; Nikolova, M.; Kotsev, T.; Mollov, M.; Swain, C.; Environ. Pollut. 2010, 158, 2158.

33. Flegal, A. R.; Patterson, C. C.; Earth Planet. Sci. Lett. 1983, 4, 19.

34. Bindler, R.; Renberg, I.; Anderson, N. J.; Appleby, P. G.; Emteryd, O.; Boyle, J.; Atmos. Environ. 2001, 35, 4675. 